\title{
Laterally Confined Graphene Nanosheets and Graphene/SnO Composites as High-Rate Anode Materials for Lithium-Ion Batteries
}

\author{
Zhiyong Wang ${ }^{1}$, Hao Zhang ${ }^{2}$, Nan $\mathrm{Li}^{1}$, Zujin Shi ${ }^{1}(\varangle)$, Zhennan $\mathrm{Gu}^{1}$, and Gaoping $\mathrm{Cao}^{2}$ \\ ${ }^{1}$ Beijing National Laboratory for Molecular Sciences, State Key Lab of Rare Earth Materials Chemistry and Applications, College of \\ Chemistry and Molecular Engineering, Peking University, Beijing 100871, China \\ ${ }^{2}$ Research Institute of Chemical Defense, West Building, 35 Huayuanbei Road, Beijing 100083, China
}

Received: 9 June 2010 / Revised: 1 September 2010 / Accepted: 2 September 2010

C The Author(s) 2010. This article is published with open access at Springerlink.com

\begin{abstract}
High-rate anode materials for lithium-ion batteries are desirable for applications that require high power density. We demonstrate the advantageous rate capability of few-layered graphene nanosheets, with widths of 100-200 nm, over micro-scale graphene nanosheets. Possible reasons for the better performance of the former include their smaller size and better conductivity than the latter. Combination of $\mathrm{SnO}_{2}$ nanoparticles with graphene was used to further improve the gravimetric capacities of the electrode at high charge-discharge rates. Furthermore, the volumetric capacity of the composites was substantially enhanced compared to pristine graphene due to the higher density of the composites.
\end{abstract}

\section{KEYWORDS}

Carbon, graphene, anode, lithium-ion batteries, $\mathrm{SnO}_{2}$, nanomaterials

\section{Introduction}

High-rate performance of lithium-ion batteries is vital to applications that require high power density such as electric/hybrid vehicles and portable power tools, and thus much effort has been devoted to the exploration of high-rate materials [1-3]. It is known that the solid state diffusion of lithium ions in the active electrode materials is the rate-limiting step in most cases [4,5]. Accordingly, shortening the distance of lithium-ion diffusion is an effective route to improve the rate performance of batteries, which can be realized by fabrication of nanostructured electrodes. For example, nanostructured $\mathrm{SnO}_{2}, \mathrm{~V}_{2} \mathrm{O}_{5}$, and $\mathrm{TiO}_{2}$ anode materials manifest better rate capabilities than corresponding thin film or bulk counterparts [6-11].

The rate performance of currently commercial carbonaceous anode materials needs to be improved to generate higher power density, however. It has been demonstrated that small-size graphites exhibit higher capacities than large-size graphites at high chargedischarge rates [12]. Furthermore, the porous structure of carbon nanomaterials, which facilitates the transport of lithium ions in the electrolyte, is crucial for improving the rate performance of the batteries [13-16]. Among the various kinds of carbonaceous anode materials, graphene has newly emerged as one with exceptional properties [17]. The larger interlayer

Address correspondence to zjshi@pku.edu.cn 
distance of few-layered graphene nanosheets compared with graphite leads to graphene having a higher capacity than the theoretical value of graphite (372 $\mathrm{mA} \cdot \mathrm{h} / \mathrm{g}$ [18], corresponding to a stoichiometric composition $\mathrm{LiC}_{6}$ ) [17]. The good conductivity and flexibility of graphene nanosheets make them suitable for fabrication into high-performance composites with other anode materials such as $\mathrm{SnO}_{2}$ and $\mathrm{TiO}_{2}[19,20]$. The width of these graphene nanosheets is usually on the micro scale. It is expected that the performance of the graphene nanosheets would be enhanced if their sizes are reduced, as a result of the shortening of the lithium-ion diffusion path. We have recently synthesized high-purity graphene nanosheets with small size of $\sim 100-200 \mathrm{~nm}$, so called laterally confined graphene nanosheets [21]. In this article, we demonstrate the exceptional rate capability of this kind of graphene nanosheets. The reversible capacity of the laterally confined graphene nanosheets at high charge-discharge rates is much higher than that of micro-scale graphene. Moreover, the gravimetric and volumetric capacities are both improved by loading $\mathrm{SnO}_{2}$ nanoparticles on the graphene nanosheets. These results show the great promise of the laterally confined graphene nanosheets and graphene-based composites in lithium-ion batteries with high power density.

\section{Experimental}

\subsection{Material preparation}

The laterally confined graphene nanosheets were produced by arc-discharge evaporation of graphite in a $\mathrm{NH}_{3}-\mathrm{He}$ mixed atmosphere [21]. $\mathrm{SnO}_{2}$ nanoparticles were loaded onto graphene nanosheets by hydrolysis of $\mathrm{SnCl}_{4}$ [19]. Typically, $\mathrm{NaOH}$ aqueous solution (0.106 $\mathrm{mol} / \mathrm{L}, 50 \mathrm{~mL}$ ) was added dropwise into an aqueous solution of $\mathrm{SnCl}_{4}(0.054 \mathrm{~mol} / \mathrm{L}, 50 \mathrm{~mL})$ under stirring. The resulting hydrosol was mixed with $200 \mathrm{mg}$ of graphene dispersed in ethylene glycol. After $3 \mathrm{~h}$, several drops of $\mathrm{H}_{2} \mathrm{SO}_{4}(0.1 \mathrm{~mol} / \mathrm{L})$ were added to the solution. The precipitate was separated from the solution by centrifugation and heated at $400{ }^{\circ} \mathrm{C}$ for $2 \mathrm{~h}$ in a $\mathrm{Ar}$ atmosphere. Micro-scale graphene nanosheets were produced by reduction of graphene oxide in a $\mathrm{H}_{2}-\mathrm{Ar}$ atmosphere at $800^{\circ} \mathrm{C}$ for $1 \mathrm{~h}$. The graphene oxide was obtained by chemical exfoliation of graphite [22].

\subsection{Characterization and electrochemical tests}

The morphology and structure of the laterally confined graphene nanosheets were examined by scanning electron microscopy (SEM, JEOL JEM-7401) and transmission electron microscopy (TEM, Hitachi H-9000NAR). X-ray diffraction (XRD) patterns were recorded on a Rigaku D/MAX 2000 diffractometer using $\mathrm{Cu} \mathrm{K \alpha}$ radiation. Pore size distributions of the laterally confined graphene nanosheets were obtained from analysis of the desorption branch of the nitrogen sorption isotherms at $77 \mathrm{~K}$ (Shimadzu, Micrometrics ASAP 2010) using density functional theory. The content of $\mathrm{SnO}_{2}$ in the graphene/ $\mathrm{SnO}_{2}$ composites was determined by thermogravimetric analysis performed on a Q50TGA analyzer (Thermal Analysis Inc.) from room temperature to $900{ }^{\circ} \mathrm{C}$ at a rate of $10^{\circ} \mathrm{C} / \mathrm{min}$ under an air flow of $30 \mathrm{~mL} / \mathrm{min}$. Cyclic voltammetry measurements were carried out by using three-electrode cells with lithium metal as the counter and reference electrodes. Galvanostatic measurements were carried out by using two-electrode cells with lithium metal as the counter electrode. The working electrodes were fabricated by compressing the mixture of $90 \mathrm{wt} \%$ active materials (graphene nanosheets $\left(1.5 \mathrm{mg} / \mathrm{cm}^{2}\right.$ ) or graphene $/ \mathrm{SnO}_{2}$ composites $\left(4.0 \mathrm{mg} / \mathrm{cm}^{2}\right)$ ) and $10 \mathrm{wt} \%$ polytetrafluoroethylene onto a copper foil. The working electrodes were dried in vacuum at $120^{\circ} \mathrm{C}$ for at least $4 \mathrm{~h}$ and then assembled as cells in an Ar-filled glovebox (MBRAUN, UNIlab, Germany). The electrolyte used was $1.0 \mathrm{~mol} / \mathrm{L}$ $\mathrm{LiPF}_{6}$ in a 50:50 $(\mathrm{v} / \mathrm{v})$ mixture of ethylene carbonate and dimethyl carbonate. Cyclic voltammograms were recorded from 3.0 and $0.05 \mathrm{~V}$ at $0.5 \mathrm{mV} / \mathrm{s}$, by using a Solartron $1280 \mathrm{Z}$ electrochemical workstation. The charge-discharge measurements were carried using an Arbin BT-2000 system. Galvanostatic cycling was performed between 3.0 and $0.05 \mathrm{~V}$ at various rates to evaluate the rate and cycle performance. All measurements were carried out at room temperature.

\section{Results and discussion}

Exposed edges of the graphene nanosheets are visible in the SEM image shown in Fig. 1(a). The random arrangement of the nanosheets leads to the formation 


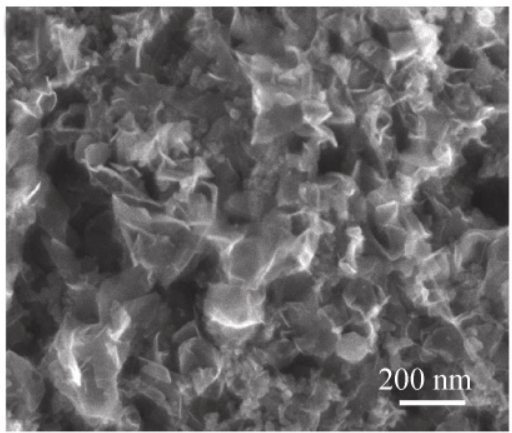

(a)

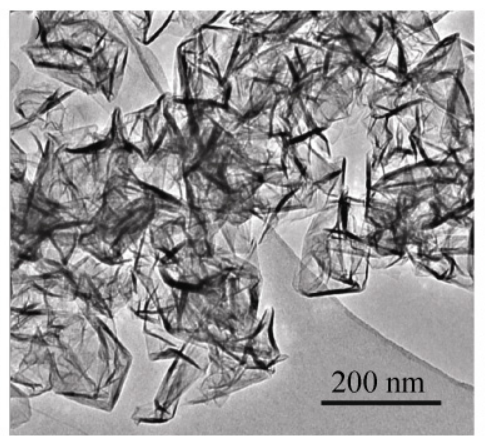

(b)

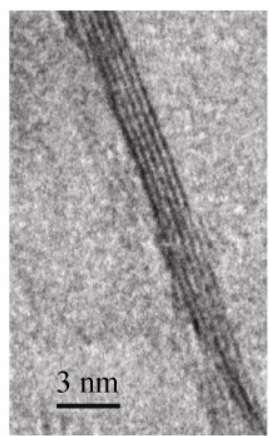

(c)

Figure 1 (a) SEM and (b) TEM image of the laterally confined graphene nanosheets. (c) High-magnification TEM image showing a five-layered graphene nanosheet

of a porous structure that contains both micropores and mesopores (Fig. S-1 in the Electronic Supplementary Material (ESM)), which should favor the diffusion of lithium ions in the electrolyte to the carbon surface. A TEM image (Fig. 1(b)) shows that the widths of the graphene nanosheets are typically $100-200 \mathrm{~nm}$. Closer inspection revealed that the layer numbers of the nanosheets are mainly in the range from two to six. Figure 1(c) shows a five-layered graphene.

Cyclic voltammetry was employed to study the electrochemical properties of the graphene nanosheets. Figure 2(a) shows the first five cyclic voltammograms of the graphene nanosheets at a rate of $0.5 \mathrm{mV} / \mathrm{s}$ in the voltage window 3.0-0.05 V. The reduction and oxidation peaks correspond to the insertion and extraction of lithium ions into/from graphene layers respectively. The remarkable intensity difference between the first and the second reductive sweep indicates a large irreversible capacity, which can be attributed to the decomposition of the electrolyte and the formation of a solid electrolyte interface layer on the carbon surface.

Cycle performance and rate capability of the graphene nanosheets were examined in order to evaluate their potential as anode materials for lithium-ion batteries. The results are shown in Fig. 2(b). The charge-discharge current density was increased stepwise from 65 to $16000 \mathrm{~mA} / \mathrm{g}$ and ten cycles were performed at each current density. After the measurements at $16000 \mathrm{~mA} / \mathrm{g}$, the current density was decreased to $65 \mathrm{~mA} / \mathrm{g}$ in order to test the reversibility and cycle stability. The graphene nanosheets delivered a reversible capacity of $339 \mathrm{~mA} \cdot \mathrm{h} / \mathrm{g}$ in the first cycle, which is close to the theoretical capacity of graphite $(372 \mathrm{~mA} \cdot \mathrm{h} / \mathrm{g})$. The capacity was not very stable in the first ten cycles where fluctuations in the range $339-319 \mathrm{~mA} \cdot \mathrm{h} / \mathrm{g}$ were observed. When the current density was increased to $550 \mathrm{~mA} / \mathrm{g}$, the graphene nanosheets delivered a capacity of $275 \mathrm{~mA} \cdot \mathrm{h} / \mathrm{g}$, which is $81 \%$ of the initial capacity. When the current density was increased to 2500 and $6500 \mathrm{~mA} / \mathrm{g}$, capacities of 250 and $184 \mathrm{~mA} \cdot \mathrm{h} / \mathrm{g}$, respectively, were obtained. Surprisingly, a relatively high capacity of $130 \mathrm{~mA} \cdot \mathrm{h} / \mathrm{g}$ was obtained at 10000 $\mathrm{mA} / \mathrm{g}$, (corresponding to a charge-discharge time of $47 \mathrm{~s})$. A capacity of $32 \mathrm{~mA} \cdot \mathrm{h} / \mathrm{g}$ was retained when the current density was elevated to $16000 \mathrm{~mA} / \mathrm{g}$. To the best of our knowledge, the rate performance of the graphene nanosheets is better than other carbonaceous anodes reported previously [13-16, 23]. Good cyclic performance is confirmed by the fact that relatively stable capacity was obtained at each rate and the capacity after reducing the current density back to $65 \mathrm{~mA} / \mathrm{g}$ was a little higher than the initial capacity. Figure 2(c) shows the charge-discharge curves of the laterally confined graphene nanosheets at low and high current densities. There is no obvious voltage plateau and the discharging capacity mainly originates in the voltage range 1.5-0.05 V.

For comparison, we also investigated the rate capability of micro-scale graphene obtained from reduction of graphene oxide. Figure 3(a) shows a lowmagnification TEM image of the micro-scale graphene. The micro-scale graphene consists of multi-layered nanosheets, as shown by the high-magnification TEM 


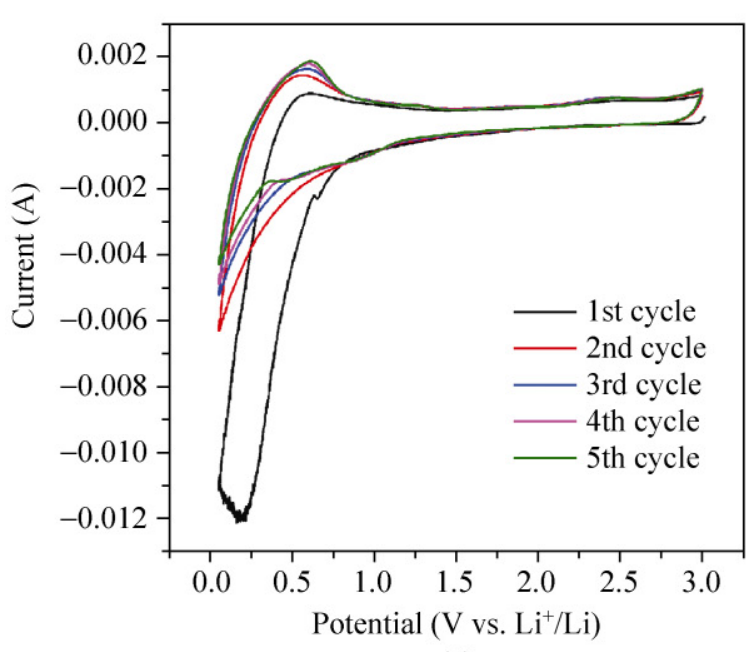

(a)

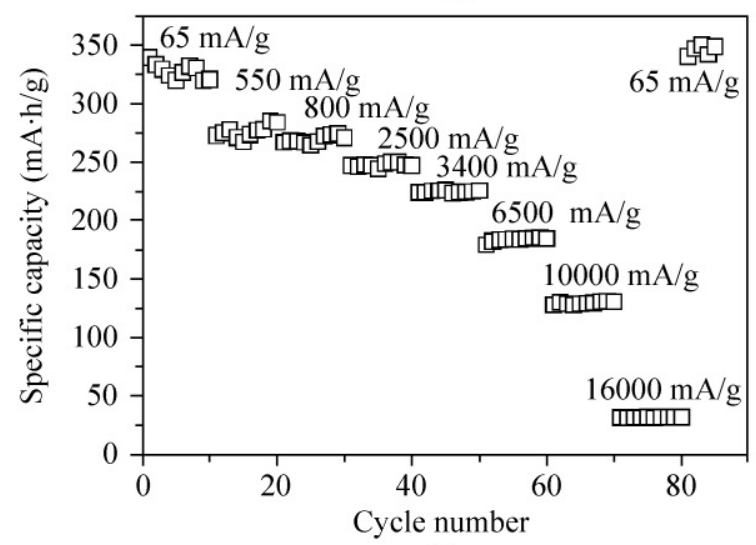

(b)

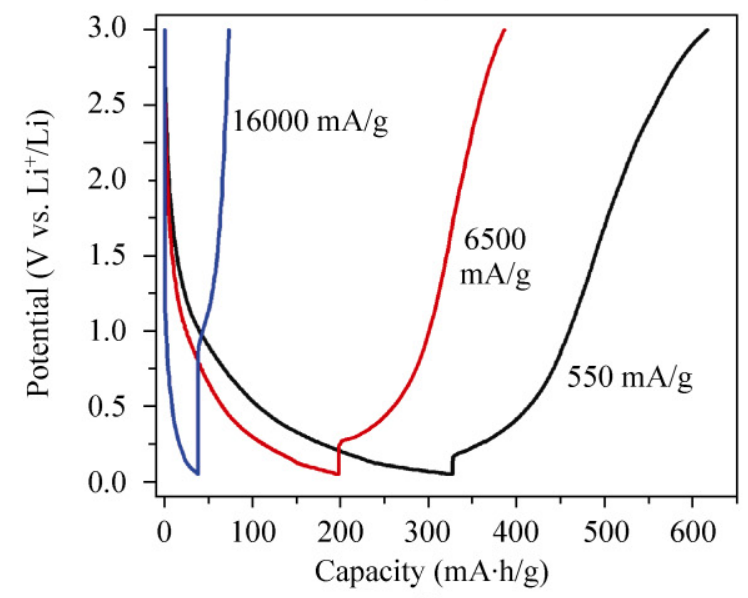

(c)

Figure 2 (a) The first five cyclic voltammograms of the laterally confined graphene nanosheets at a rate of $0.5 \mathrm{mV} / \mathrm{s}$ in the voltage window of 3.0-0.05 V. (b) Cycle performance of the laterally confined graphene nanosheets at various charge-discharge current densities. (c) Charge-discharge curves at current densities of 550, 6500 , and $16000 \mathrm{~mA} / \mathrm{g}$ image (Fig. 3(b)). The rate performance of the microscale graphene is shown in Fig. 3(c). At a low current density of $65 \mathrm{~mA} / \mathrm{g}$, the capacity was comparable to that of laterally confined graphene nanosheets. However, at high charge-discharge rates, the capacity was substantially lower than that of laterally confined graphene nanosheets. The capacity of micro-scale graphene nanosheets at $2000 \mathrm{~mA} / \mathrm{g}(68 \mathrm{~mA} \cdot \mathrm{h} / \mathrm{g})$ was only $27 \%$ of that $(250 \mathrm{~mA} \cdot \mathrm{h} / \mathrm{g})$ of laterally confined graphene nanosheets at $2500 \mathrm{~mA} / \mathrm{g}$. The charge-discharge curves of the micro-scale graphene nanosheets at current densities of 200 and $400 \mathrm{~mA} / \mathrm{g}$ are depicted in Fig. 3(d). Similar to the curves for the laterally confined graphene nanosheets, no distinct voltage plateau was observed. Possible reasons for the superior rate capability of the laterally confined graphene nanosheets are their smaller size and better conductivity with respect to the micro-scale counterparts. The length of transport path for lithium ions is shortened in the case of small-size nanosheets and the smaller size leads to a larger solid-electrolyte interface, which facilitates the transport of lithium ions. During the charge-discharge process, lithium ions are inserted/extracted from the open edge of graphene layers. Thus, the presence of more edges in graphene nanosheets leads to higher insertion/extraction rates. Assuming that a square graphene nanosheet with a width of $1 \mu \mathrm{m}$ is divided into smaller pieces of square nanosheets with widths of $100 \mathrm{~nm}$, the overall length of the edges is increased five-fold. Another factor that may affect the rate capability of the graphene nanosheets is their conductivity. Impedance measurements showed that the conductivity of the laterally confined graphene nanosheets was much better than that of the micro-scale graphene nanosheets (Fig. 3(e)). The lower conductivity of the latter is a consequence of residual oxygenated groups on the graphene. The oxygenated groups cannot be removed completely during the reduction process in a $\mathrm{H}_{2}-\mathrm{Ar}$ atmosphere.

The main disadvantage of the carbonaceous anode material is that its capacity is relatively low (theoretical capacity: $372 \mathrm{~mA} \cdot \mathrm{h} / \mathrm{g}$ ). A widely used route to circumvent this problem is to combine carbonaceous materials with other high-capacity materials, for 


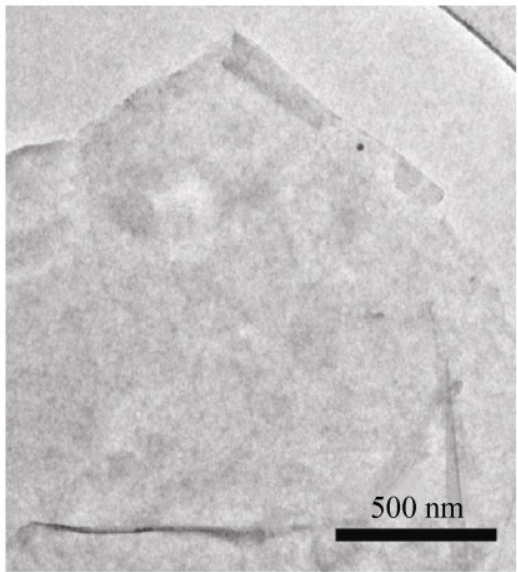

(a)

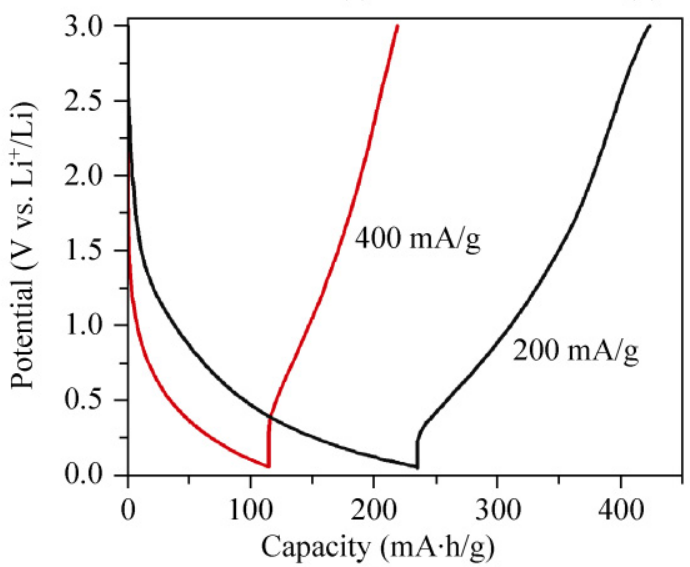

(d)

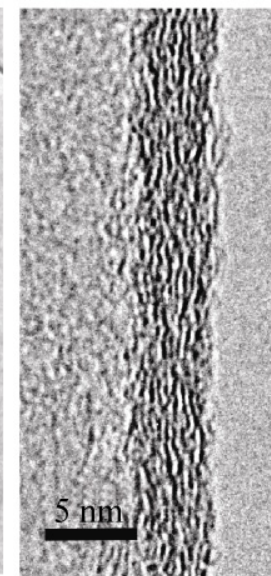

(b)

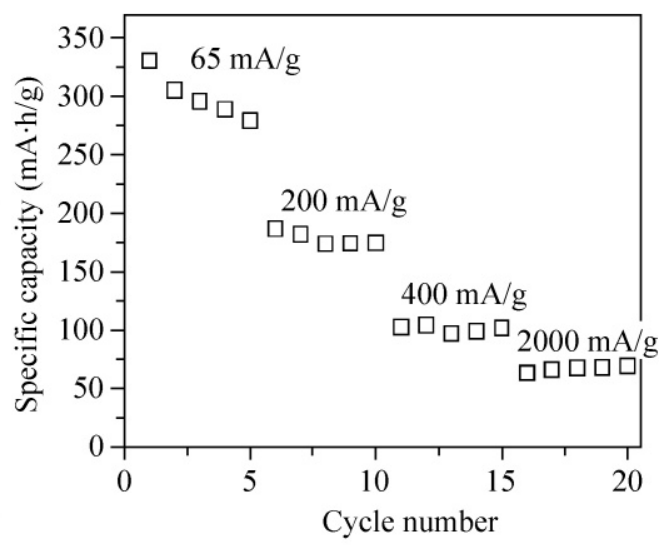

(c)

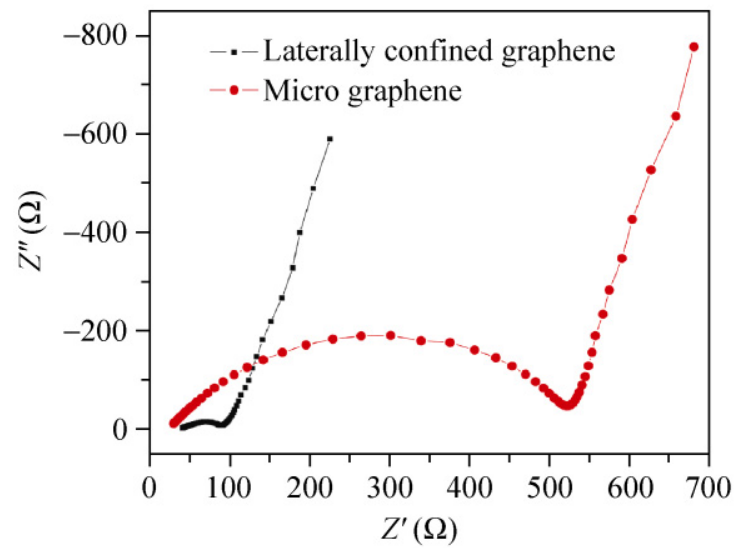

(e)

Figure 3 (a) Low-magnification and (b) high-magnification TEM images of micro-scale graphene nanosheets. (c) Cycle performance of micro-scale graphene nanosheets. (d) Charge-discharge curves of micro-scale graphene nanosheets at current densities of 200 and $400 \mathrm{~mA} / \mathrm{g}$. (e) Impedance plots of laterally confined and micro-scale graphene nanosheets

example Sn (theoretical capacity: $992 \mathrm{~mA} \cdot \mathrm{h} / \mathrm{g}$ ) and $\mathrm{SnO}_{2}$ (theoretical capacity: $782 \mathrm{~mA} \cdot \mathrm{h} / \mathrm{g}$ [24-27]. In the case of nanostructured high-capacity materials dispersed in a carbon matrix, the latter serves as a buffer to alleviate the strain caused by the volume change of the former during the charge-discharge process. Herein we take graphene/SnO $\mathrm{S}_{2}$ composites as an example to demonstrate the applicability of this route for fabrication of anode materials with high capacity and good rate performance based on laterally confined graphene nanosheets. Adhesion of $\mathrm{SnO}_{2}$ nanoparticles to graphene nanosheets was confirmed by TEM and XRD. A lowmagnification TEM image (Fig. 4(a)) shows $\mathrm{SnO}_{2}$ particles with diameter of $\sim 4 \mathrm{~nm}$ distributed on the surface of the graphene nanosheets. The sample was treated by sonication in ethanol before TEM observation, so the $\mathrm{SnO}_{2}$ particles are thought to be strongly anchored on the surface of the graphene. A high-magnification TEM image (Fig. 4(b)) shows that the $\mathrm{SnO}_{2}$ particles are well crystallized. The XRD pattern of the composites (Fig. 4(c)) reveals a tetragonal rutile-like phase of $\mathrm{SnO}_{2}$ (JCPDS Card No 41-1445). The content of $\mathrm{SnO}_{2}$ in the composites was determined to be $67 \mathrm{wt} \%$ from thermogravimetric analysis (Fig. S-2 in the ESM). The small size of the $\mathrm{SnO}_{2}$ particles ensures high-rate insertion/ extraction of lithium ions.

Cyclic voltammograms of the graphene/ $/ \mathrm{SnO}_{2} \mathrm{com}-$ posites at a rate of $0.5 \mathrm{mV} / \mathrm{s}$ in a voltage window of 3.0-0.05 V are shown in Fig. 5(a). In contrast with the cyclic voltammograms of the pristine graphene 


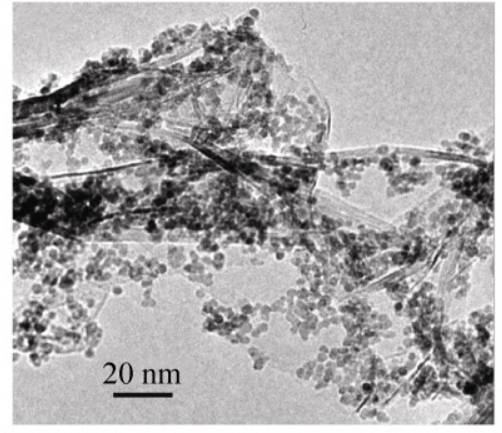

(a)

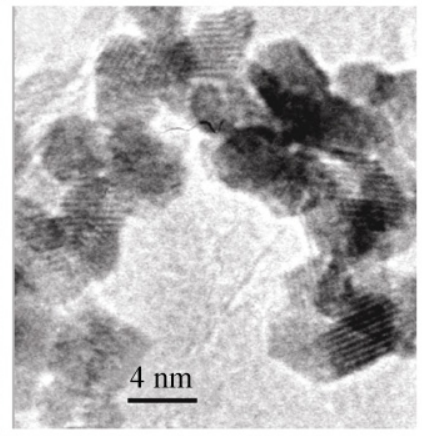

(b)

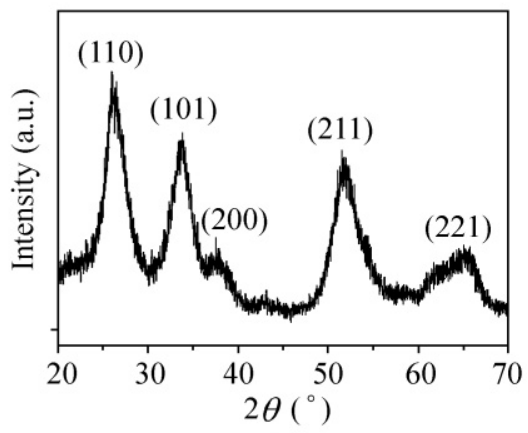

(c)

Figure 4 (a) Low-magnification and (b) high-magnification TEM images of laterally confined graphene/SnO ${ }_{2}$ composites. (c) XRD pattern of the composites

nanosheets, some new peaks are observed in Fig. 5(a). It is known that the reaction of $\mathrm{SnO}_{2}$ involves a twostep process: (1) reduction of $\mathrm{SnO}_{2}$ to $\mathrm{Sn}$; (2) alloying of $\mathrm{Sn}$ with $\mathrm{Li}$ to form a series of alloys [28-30]. The new reduction peaks in Fig. 5(a) correspond to the reduction of $\mathrm{SnO}_{2}$ to $\mathrm{Sn}$ and the formation of $\mathrm{Li}-\mathrm{Sn}$ alloys, while the oxidation peaks correspond to the reverse process.

Figures 5(b) and 5(c), respectively, show the reversible capacities and the charge-discharge curves of the graphene $/ \mathrm{SnO}_{2}$ composites at various current densities. As in the case of pristine graphene, the charge-discharge current density was increased stepwise from 130 to $8000 \mathrm{~mA} / \mathrm{g}$. After the measurements at $8000 \mathrm{~mA} / \mathrm{g}$, the current density was reduced in order to test the reversibility and cycle performance. As expected, the graphene $/ \mathrm{SnO}_{2}$ composites exhibited higher capacity than the pristine graphene at low current densities. The composite delivered an initial capacity of $673 \mathrm{~mA} \cdot \mathrm{h} / \mathrm{g}$ at $130 \mathrm{~mA} / \mathrm{g}$. The capacity was gradually reduced to $513 \mathrm{~mA} \cdot \mathrm{h} / \mathrm{g}$ during the first 10 cycles. The capacities at $450,1400,6000$, and $8000 \mathrm{~mA} / \mathrm{g}$ were $424,295,190$, and $120 \mathrm{~mA} \cdot \mathrm{h} / \mathrm{g}$, respectively. The cycle and rate performance of the graphene $/ \mathrm{SnO}_{2}$ composites were much better than for pure $\mathrm{SnO}_{2}$ nanoparticles (Fig. S-3 in the ESM), because the graphene can prevent the large volume change and pulverization of the electrode which occurs in the case of pure $\mathrm{SnO}_{2}$. When the current density was lowered to $450 \mathrm{~mA} / \mathrm{g}$, the composites delivered a capacity of $403 \mathrm{~mA} \cdot \mathrm{h} / \mathrm{g}$, retaining $93 \%$ of the capacity obtained at $450 \mathrm{~mA} / \mathrm{g}$ in the 20th cycle. It should be noted that the capacity retention of the graphene/ $\mathrm{SnO}_{2}$ composites was not as good as for the pristine graphene. This may be caused by the aggregation and detachment of $\mathrm{SnO}_{2}$ nanoparticles to some degree. Although the $\mathrm{SnO}_{2}$ nanoparticles are dispersed on the surface of the graphene nanosheets, the particles are still able to aggregate during the chargedischarge process. Compared with a $\mathrm{SnO}_{2} @$ carbon core-shell structure, $\mathrm{SnO}_{2}$ dispersed on graphene in the present study may undergo aggregation and detachment due to the open structure [27].

In order to conveniently compare the rate capability of the laterally confined graphene and graphene $/ \mathrm{SnO}_{2}$ composites, the gravimetric capacities are plotted as a function of charge-discharge rate in Fig. 6(a). The capacity of graphene $/ \mathrm{SnO}_{2}$ composites was substantially higher than that of graphene nanosheets at low current densities. However, the superiority of the composites diminished as the current density increased. Graphene nanosheets exhibited larger capacity than the composite at very rates. We also investigated the rate capability of micro-scale graphene nanosheets loaded with $\mathrm{SnO}_{2}$ nanoparticles. The micro-graphene/ $/ \mathrm{SnO}_{2}$ composites exhibited comparable capacities to the laterally confined graphene/ $\mathrm{SnO}_{2}$ composites at 130 $\mathrm{mA} / \mathrm{g}$. However, the capacity of the micro-graphene/ $\mathrm{SnO}_{2}$ composites was lower than for the laterally confined graphene/SnO ${ }_{2}$ composites at high chargedischarge rates (Fig. S-4 in the ESM). This may be associated with the low capacity of micro-graphene at high rates. 


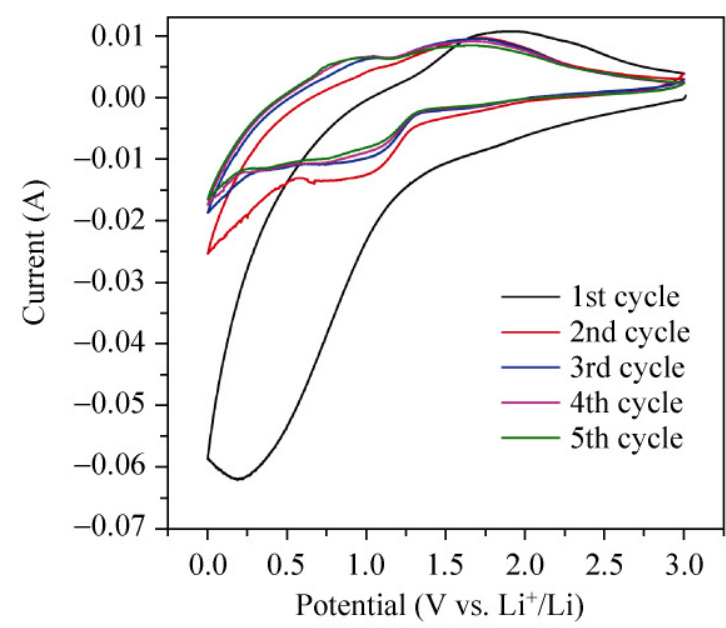

(a)

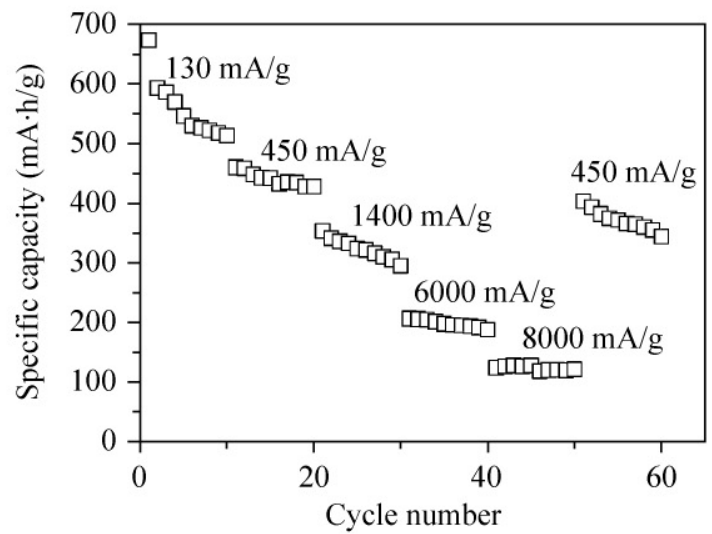

(b)

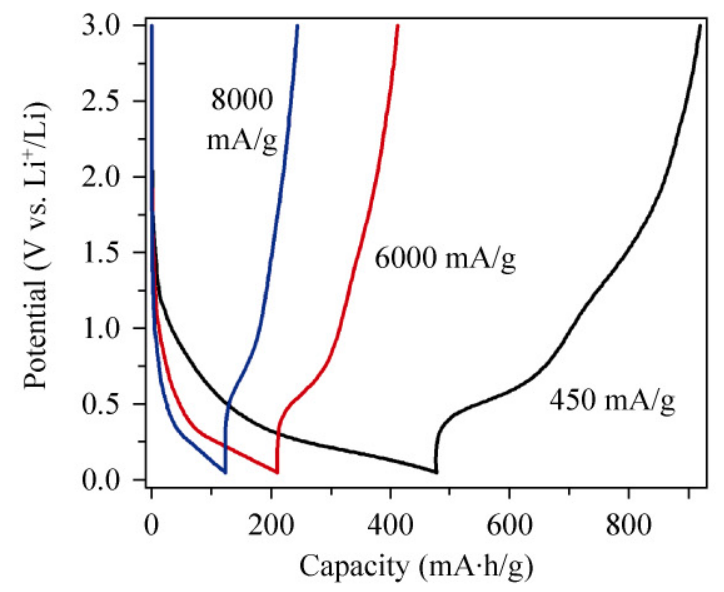

(c)

Figure 5 (a) The first five cyclic voltammograms of the laterally confined graphene $/ \mathrm{SnO}_{2}$ composites at a rate of $0.5 \mathrm{mV} / \mathrm{s}$ in the voltage window of $3.0-0.05 \mathrm{~V}$. (b) Cycle performance of the graphene/ $\mathrm{SnO}_{2}$ composites at various charge-discharge current densities. (c) Charge-discharge curves at current densities of 450 , 6000 , and $8000 \mathrm{~mA} / \mathrm{g}$

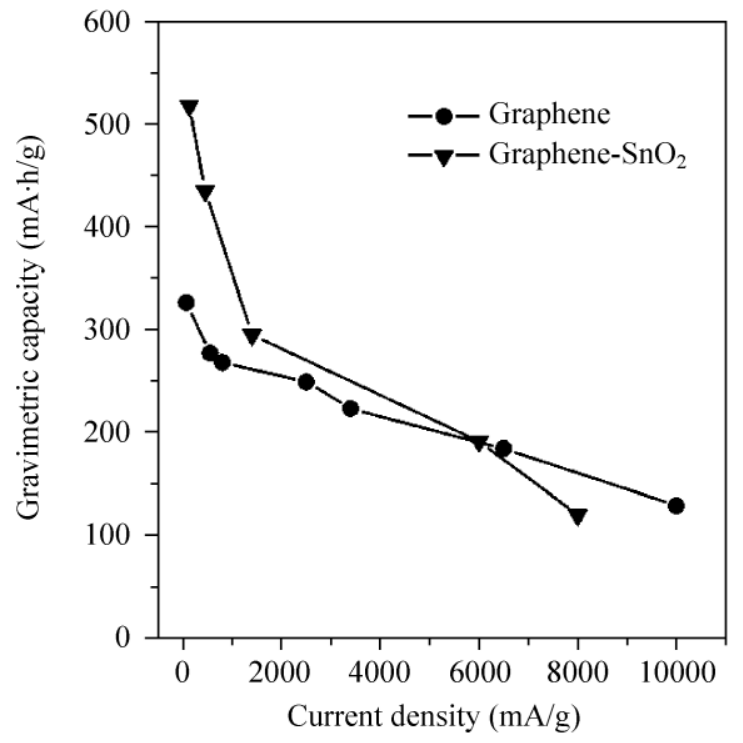

(a)

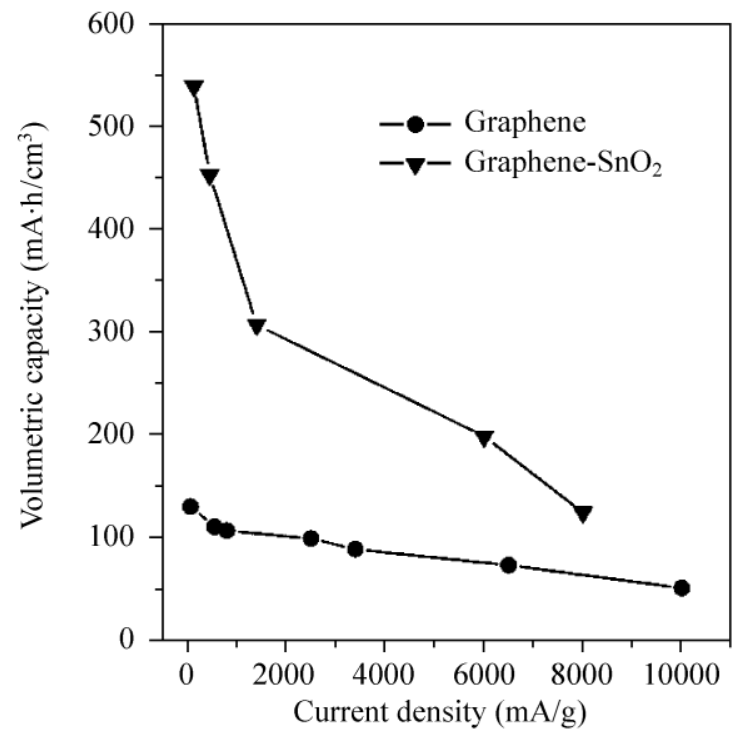

(b)

Figure 6 (a) Gravimetric and (b) volumetric capacities of laterally confined graphene and graphene/ $\mathrm{SnO}_{2}$ composites at various current densities

From a practical viewpoint, the volumetric energy density is an important parameter for a battery. In the case of laterally confined graphene nanosheets and graphene $/ \mathrm{SnO}_{2}$ composites used in the present study, the latter has a higher density than the former (1.04 vs. $0.40 \mathrm{~g} / \mathrm{cm}^{3}$ ). Figure $6(\mathrm{~b})$ depicts the volumetric capacities of the two materials at various chargedischarge rates. It is obvious that the volumetric capacities of the graphene/ $\mathrm{SnO}_{2}$ composites are considerably higher than those of the graphene. Therefore, 
graphene $/ \mathrm{SnO}_{2}$ composite is a suitable candidate when high rate and small volume are required.

\section{Conclusions}

Laterally confined graphene nanosheets with size of 100-200 nm exhibit much better rate performance than micro-scale graphene as anode materials in lithium-ion batteries. Capacities of 184 and $130 \mathrm{~mA} \cdot \mathrm{h} / \mathrm{g}$ were obtained at high current densities of 6500 and 10000 $\mathrm{mA} / \mathrm{g}$ when using the smaller graphene nanosheets. Loading $\mathrm{SnO}_{2}$ nanoparticles onto the graphene nanosheets was used to improve the capacity of the anode. The gravimetric and volumetric capacities of the composites were substantially improved compared to pristine graphene. Our study demonstrates that laterally confined graphene nanosheets and graphenebased composites hold a great promise as high-rate anode materials for lithium-ion batteries. Besides $\mathrm{SnO}_{2}$, the performance of the graphene nanosheets can also be improved by combination with other materials (such as $\mathrm{CuO}, \mathrm{MnO}_{2}$, and $\mathrm{Si}$ ) to meet the demands for specific applications.

\section{Acknowledgements}

The authors gratefully acknowledge the National Natural Science Foundation of China (Nos. 90206048 and 20371004) and the Ministry of Science and Technology of China (Grant Nos. 2006CB932701 and 2007AA03Z311) for financial support.

Electronic Supplementary Material: Supplementary material (pore size distribution of the laterally confined graphene, thermogravimetric trace of the composites of laterally confined graphene and $\mathrm{SnO}_{2}$, TEM image and cycle performance of $\mathrm{SnO}_{2}$ nanoparticles and micrographene $/ \mathrm{SnO}_{2}$ composites) is available in the online version of this article at http://dx.doi.org/10.1007/s12274010-0041-5 and is accessible free of charge.

Open Access: This article is distributed under the terms of the Creative Commons Attribution Noncommercial License which permits any noncommercial use, distribution, and reproduction in any medium, provided the original author(s) and source are credited.

\section{References}

[1] Whittingham, M. S. Lithium batteries and cathode materials. Chem. Rev. 2004, 104, 4271-4301.

[2] Kang, K. S.; Meng, Y. S.; Breger, J.; Grey, C. P.; Ceder, G. Electrodes with high power and high capacity for rechargeable lithium batteries. Science 2006, 311, 977-980.

[3] Lee, Y. J.; Yi, H.; Kim, W.; Kang, K.; Yun, D. S.; Strano, M. S.; Ceder, G.; Belcher, A. M. Fabricating genetically engineered high-power lithium-ion batteries using multiple virus genes. Science 2009, 324, 1051-1055.

[4] Levi, M. D.; Aurbach, D. Diffusion coefficients of lithium ions during intercalation into graphite derived from the simultaneous measurements and modeling of electrochemical impedance and potentiostatic intermittent titration characteristics of thin graphite electrodes. J. Phys. Chem. B 1997, 101, 4641-4647.

[5] Bueno, P. R.; Leite, E. R. Nanostructured Li ion insertion electrodes. 1. Discussion on fast transport and short path for ion diffusion. J. Phys. Chem. B 2003, 107, 8868-8877.

[6] Li, N. C.; Martin, C. R.; Scrosati, B. Nanomaterial-based Li-ion battery electrodes. J. Power Sources 2001, 97-98, 240-243.

[7] Sides, C. R.; Martin, C. R. Nanostructured electrodes and the low-temperature performance of Li-ion batteries. $A d v$. Mater. 2005, 17, 125-128.

[8] Patrissi, C. J.; Martin, C. R. Improving the volumetric energy densities of nanostructured $\mathrm{V}_{2} \mathrm{O}_{5}$ electrodes prepared using the template method. J. Electrochem. Soc. 2001, 148, A1247-A1253.

[9] Fu, L. J.; Zhang, T.; Cao, Q.; Zhang, H. P.; Wu, Y. P. Preparation and characterization of three-dimensionally ordered mesoporous titania microparticles as anode material for lithium ion battery. Electrochem. Commun. 2007, 9, 2140-2144.

[10] Hu, Y. S.; Kienle, L.; Guo, Y. G.; Maier, J. High lithium electroactivity of nanometer-sized rutile $\mathrm{TiO}_{2}$. Adv. Mater. 2006, 18, 1421-1426.

[11] Armstrong, A. R.; Armstrong, G.; Canales, J.; Garcia, R.; Bruce, P. G. Lithium-ion intercalation into $\mathrm{TiO}_{2}$-B nanowires. Adv. Mater. 2005, 17, 862-865.

[12] Zaghib, K.; Brochu, F.; Guerfi, A.; Kinoshita, K. Effect of particle size on lithium intercalation rates in natural graphite. J. Power Sources 2001, 103, 140-146.

[13] Hu, Y. S.; Adelhelm, P.; Smarsly, B. M.; Hore, S.; Antonietti, M.; Maier, J. Synthesis of hierarchically porous carbon monoliths with highly ordered microstructure and their application in rechargeable lithium batteries with high-rate capability. Adv. Funct. Mater. 2007, 17, 1873-1878. 
[14] Li, N. C.; Mitchell, D. T.; Lee, K. P.; Martin, C. R. A nanostructured honeycomb carbon anode. J. Electrochem. Soc. 2003, 150, A979-A984.

[15] Lee, K. T.; Lytle, J. C.; Ergang, N. S.; Oh, S. M.; Stein, A. Synthesis and rate performance of monolithic macroporous carbon electrodes for lithium-ion secondary batteries. $A d v$. Funct. Mater. 2005, 15, 547-556.

[16] Zhang, F.; Wang, K. X.; Li, G. D.; Chen, J. S. Hierarchical porous carbon derived from rice straw for lithium ion batteries with high-rate performance. Electrochem. Commun. 2009, 11, 130-133.

[17] Yoo, E.; Kim, J.; Hosono, E.; Zhou, H.; Kudo, T.; Honma, I. Large reversible Li storage of graphene nanosheet families for use in rechargeable lithium ion batteries. Nano Lett. 2008, 8, 2277-2282.

[18] Tatsumi, K.; Iwashita, N.; Sakaebe, H.; Shioyama, H.; Higuchi, S.; Mabuchi, A.; Fujimoto, H. The influence of the graphitic structure on the electrochemical characteristics for the anode of secondary lithium batteries. J. Electrochem. Soc. 1995, 142, 716-720.

[19] Paek, S. M.; Yoo, E.; Honma, I. Enhanced cyclic performance and lithium storage capacity of $\mathrm{SnO}_{2} /$ graphene nanoporous electrodes with three-dimensionally delaminated flexible structure. Nano Lett. 2009, 9, 72-75.

[20] Wang, D. H.; Choi, D. W.; Li, J.; Yang, Z. G.; Nie, Z. M.; Kou, R.; Hu, D. H.; Wang, C. M.; Saraf, L. V.; Zhang, J. G.; Aksay, I. A.; Liu, J. Self-assembled $\mathrm{TiO}_{2}$-graphene hybrid nanostructures for enhanced Li-ion insertion. ACS Nano 2009, 3, 907-914.

[21] Li, N.; Wang, Z. Y.; Zhao, K. K.; Shi, Z. J.; Gu, Z. N.; Xu, S. $\mathrm{K}$. Large scale synthesis of N-doped multi-layered graphene sheets by simple arc-discharge method. Carbon 2010, 48, 255-259.

[22] Stankovich, S.; Dikin, D. A.; Piner, R. D.; Kohlhaas, K. A.; Kleinhammes, A.; Jia, Y.; Wu, Y.; Nguyen, S. T.; Ruoff, R. S. Synthesis of graphene-based nanosheets via chemical reduction of exfoliated graphite oxide. Carbon 2007, 45, 1558-1565.

[23] Habazaki, H.; Kiriu, M.; Konno, H. High rate capability of carbon nanofilaments with platelet structure as anode materials for lithium ion batteries. Electrochem. Commun. 2006, 8, 1275-1279.

[24] Wang, G. X.; Ahn, J. H.; Lindsay, M. J.; Sun, L.; Bradhurst, D. H.; Dou, S. X.; Liu, H. K. Graphite-tin composites as anode materials for lithium-ion batteries. J. Power Sources 2001, 97-98, 211-215.

[25] Wen, Z. H.; Wang, Q.; Zhang, Q.; Li, J. H. In situ growth of mesoporous $\mathrm{SnO}_{2}$ on multiwalled carbon nanotubes: A novel composite with porous-tube structure as anode for lithium batteries. Adv. Funct. Mater. 2007, 17, 2772-2778.

[26] Zhang, W. M.; Hu, J. S.; Guo, Y. G.; Zheng, S. F.; Zhong, L. S.; Song, W. G.; Wan, L. J. Tin-nanoparticles encapsulated in elastic hollow carbon spheres for high-performance anode material in lithium-ion batteries. Adv. Mater. 2008, 20, 1160-1165.

[27] Lou, X. W.; Li, C. M.; Archer, L. A. Designed synthesis of coaxial $\mathrm{SnO}_{2} @$ carbon hollow nanospheres for highly reversible lithium storage. Adv. Mater. 2009, 21, 25362539.

[28] Courtney, I. A.; Dahn, J. R. Electrochemical and in situ $\mathrm{X}$-ray diffraction studies of the reaction of lithium with tin oxide composites. J. Electrochem. Soc. 1997, 144, 20452052.

[29] Sivashanmugam, A.; Kumar, T. P.; Renganathan, N. G.; Gopukumar, S.; Wohlfahrt-Mehrens, M.; Garche, J. Electrochemical behavior of $\mathrm{Sn} / \mathrm{SnO}_{2}$ mixtures for use as anode in lithium rechargeable batteries. J. Power Sources 2005, 144, 197-203.

[30] Zhao, Y. M.; Zhou, Q.; Liu, L.; Xu, J.; Yan, M. M.; Jiang, Z. $\mathrm{Y}$. A novel and facile route of ink-jet printing to thin film $\mathrm{SnO}_{2}$ anode for rechargeable lithium ion batteries. Electrochim. Acta 2006, 51, 2639-2645. 